\title{
Physical Education Teachers' Opinion about Online Teaching during the COVID-19 Pandemic-Comparative Study of European Countries
}

\author{
Agata Korcz ${ }^{1, *(\mathbb{D}}$, Jana Krzysztoszek ${ }^{1}\left(\mathbb{D}\right.$, Marlena Lopatka $^{1}$, Biljana Popeska ${ }^{2} \mathbb{D}$, Hrvoje Podnar ${ }^{3}$, Bijen Filiz $^{4}$, \\ Eleonora Mileva ${ }^{5}$, Artan R. Kryeziu ${ }^{6}$ and Michał Bronikowski ${ }^{1}$ \\ 1 Department of Didactics of Physical Activity, Poznan University of Physical Education, \\ Królowej Jadwigi 27/39, 61-871 Poznan, Poland; krzysztoszek@awf.poznan.pl (J.K.); \\ lopatka@awf.poznan.pl (M.Ł.); bronikowski.michal.wilk@gmail.com (M.B.) \\ 2 Faculty of Educational Sciences, Goce Delcev University, 2000 Stip, North Macedonia; \\ biljana.popeska@ugd.edu.mk \\ 3 Faculty of Kinesiology, University of Zagreb, Horvacanski zavoj 15, 10000 Zagreb, Croatia; \\ hrvoje.podnar@kif.unizg.hr \\ 4 Department of Coaching Education, ANS Campus, 03200 Afyonkarahisar, Turkey; bijenfiliz@gmail.com \\ 5 The National Sports Academy "Vassil Levski", Academic Stefan Mladenov 21, 1710 Sofia, Bulgaria; \\ emileva2002@yahoo.com \\ 6 Department of Sport and Movement Science, University for Business and Technology, 10000 Pristina, Kosovo; \\ artan.kryeziu@ubt-uni.net \\ * Correspondence: korcz@awf.poznan.pl
}

Citation: Korcz, A.; Krzysztoszek, J.; Łopatka, M.; Popeska, B.; Podnar, H.; Filiz, B.; Mileva, E.; Kryeziu, A.R.; Bronikowski, M. Physical Education Teachers' Opinion about Online Teaching during the COVID-19 Pandemic-Comparative Study of European Countries. Sustainability 2021, 13, 11730. https://doi.org/ $10.3390 /$ su132111730

Academic Editors: Dario Novak, Brigita Mieziene and Branislav Antala

Received: 7 September 2021

Accepted: 19 October 2021

Published: 23 October 2021

Publisher's Note: MDPI stays neutral with regard to jurisdictional claims in published maps and institutional affiliations.

Copyright: (c) 2021 by the authors. Licensee MDPI, Basel, Switzerland. This article is an open access article distributed under the terms and conditions of the Creative Commons Attribution (CC BY) license (https:/ / creativecommons.org/licenses/by/ $4.0 /)$.
Abstract: The purpose of this study was to evaluate the quality of implementation and Physical Education (PE) teachers' perceived advantages, disadvantages, and encountered difficulties of online PE teaching during the first wave of the COVID-19 pandemic. The participants were 1148 professionally active PE teachers from Poland, North Macedonia, Croatia, Turkey, Bulgaria, and Kosovo (613 female, 535 male). A cross-sectional online survey study was performed between May and September 2020 and was done online through an electronic questionnaire. Study results suggest differences in evaluation of online teaching between PE teachers from different countries: a positive evaluation of online teaching reported from teachers from Croatia, Poland, and Bulgaria, neutral in Turkey, and a negative evaluation during that period by teachers in Macedonia and Kosovo. Different ratings of advantages, disadvantages, and difficulties from the studied countries in online teaching in primary and secondary schools were also noted. A lack of proper equipment at home, a lack of proper training for information technology (IT) use, as well as use of different platforms for online teaching were among the highest-ranked difficulties during online teaching. The greatest concerns during online PE teaching were identified in terms of pupils' safety, the intellectual property of resources, and the quality of curriculum delivery. The results from the study identify the most important areas of teachers work where PE should be supported regarding online teaching.

Keywords: physical education; teacher; teaching; primary school; secondary school; pandemic; modern technology

\section{Introduction}

COVID-19, a highly contagious disease [1], affected the world in a short period of time and was declared a pandemic by the World Health Organization (WHO) [2]. The pandemic caused a crisis in the health, economic, education, political systems, and social life of all countries of the world.

Education systems worldwide were especially impacted by the pandemic, and many countries were forced to change the way education was delivered. More than $92 \%$ of students worldwide in more than 188 countries have been affected by the pandemic [3] as schools have been closed and the teaching process continued through distance learning. 
Distance learning was facilitated using various information and communication technologies (ICT) [4,5]. Teachers in countries such as Norway [6], Sweden, Spain [7], France, and Italy [8] directed educational activities remotely via digital devices or homeschooling resources in this process.

The educational systems in the countries included in this research (Poland, Bulgaria, Kosovo, Croatia, Macedonia, Turkey) were also greatly impacted by the COVID-19 pandemic. All the countries initiated a country-wide lockdown, which included the closing of schools. Since March 2020, all lessons, including Physical Education (PE), have been conducted online. There are some differences in the structure of educational systems and time allocation for PE in the studied countries. Time allocation for PE in primary schools ranged from 90-140 min per week in Bulgaria, Croatia, Kosovo, and Macedonia to 180-200 min per week in Poland and Turkey. In the majority of the systems, to teach PE in primary schools, one needs to be qualified as a primary school classroom teacher, with some countries such as Bulgaria, Macedonia, and Poland allowing only specialised PE teachers to conduct PE lessons. In Macedonia, according to new legislation from 2019, PE classes are realised through tandem teaching, delivered together by a primary school classroom teacher and a specialised PE teacher. Time allocation for PE in post-primary schools ranges from 80-90 min in Croatia, Kosovo, and Turkey to 120-135 min per week in other countries, with some countries such as Croatia and Turkey allowing additional extracurricular PE classes. PE in post-primary schools is taught by specialised PE teachers in all the studied countries. PE in all the studied countries addresses the need to provide pupils with opportunities to be physically active and develop motor competency for participation in lifelong PA, as well as the need to encourage young people to lead active and healthy lifestyles by focusing on physical, mental, intellectual, and social development.

During the first wave of the pandemic, the governments of the included countries supported the educational system in different ways. In some countries (Croatia, Macedonia, Poland, Turkey), educational programmes were broadcasted on national television or national education information networks. These programmes were mostly focused on primary education students first and were later expanded to secondary education. In all countries, education also depended on the enthusiasm and creativity of the teachers. Teachers used various ways to communicate with students, such as social media groups, instant messaging mobile applications, and educational platforms. Similarly, PE lessons were provided by sharing video recordings, live broadcasting exercise instructions, and similar resources. PE teachers were personally responsible for creating content and designing online PE lessons. The support from schools, educational boards, and governments was mainly evident in the provision of a platform where PE teachers could communicate and share their best practices and resources, while in some of the countries, PE teachers had a chance to participate in online seminars and workshops.

ICT use during PE teaching and for the purpose of promoting physical activity behaviour change of school children was researched before the pandemic. There was no clear evidence of positive effects of ICT use, but some evidence supported the implementation of ICT delivered in combination with a face-to-face approach [9]. Using exergames and wearable technology was the most dominant way of implementing ICT during PE teaching. The most successful interventions to promote physical activity included physical activity in the school curriculum, were long-term interventions, involved teachers, and had the support of families [10].

Studies have acknowledged the positive benefits of using ICT during PE teaching but highlighted the need to increase the ICT competences of PE teachers [11]. Firstly, the primary focus of the Online Physical Education (OLPE) curriculum was cognitive, indicating that the course focused on minimal physical activity [12]. Another issue, due to the uncertainty of the curriculum and the unclear application method, PE teachers had various concerns about OLPE teaching such as course contents, access to all students, taking into account individual differences, being efficient, equipment adequacy, and limitations of Internet access [12-16]. Hence, in OLPE teaching, it is a challenge for teachers to transfer 
student experiences to a virtual environment, and it is thought that they need to develop their ICT skills.

Since the unprecedented, worldwide pandemic did not allow for the extensive education of PE teachers about ICT use nor the preparation of online teaching resources, the purpose of this study was to evaluate the quality of implementation and PE teachers' perceived advantages, disadvantages, and encountered difficulties of online PE teaching during the first wave of the COVID-19 pandemic. This information could help in shaping the process of online PE teaching in the future if the pandemic continues or for the purpose of supplementing regular in-school teaching. Reported advantages and disadvantages could help strengthen the teaching process and content of the lessons to mitigate any possible difficulties that arise.

It was hypothesised that there would be differences in the quality of implementation of online PE teaching between studied countries. In addition, perceived advantages, disadvantages, and encountered difficulties during online PE teaching will probably differ due to the differences in the structure of educational systems and time allocation for PE in the studied countries.

\section{Materials and Methods}

\subsection{Participants and Procedure}

Participants in the study were 1148 professionally active PE teachers from Poland, North Macedonia, Croatia, Turkey, Bulgaria, and Kosovo (613 female, 535 male). The age of participants ranged from 24 to 69 years old $(\mathrm{M}=45.6$; $\mathrm{SD}=9.76)$. The total sample of PE teachers consisted of Polish $(n=281,24.4 \%)$, Macedonian $(n=133,11.6 \%)$, Croatians $(n=369,32.1 \%)$, Turkish $(n=124,10.8 \%)$, Bulgarian $(n=138,12.0 \%)$, and Kosovars participants $(n=103,9.0 \%)$. Table 1 shows the prevalence of demographic variables by country and for the total group.

Table 1. Demographic characteristics of the participants.

\begin{tabular}{|c|c|c|c|c|c|c|c|}
\hline $\begin{array}{l}\text { Demographic } \\
\text { Variables }\end{array}$ & $\begin{array}{c}\text { Total } \\
\text { Sample }\end{array}$ & Poland & Macedonia & Croatia & Turkey & Bulgaria & Kosovo \\
\hline $\begin{array}{l}\text { All participants } \\
(n / \%)\end{array}$ & $1148(100)$ & $281(24.4)$ & $133(11.6)$ & $369(32.1)$ & $124(10.8)$ & $138(12.0)$ & $103(9.0)$ \\
\hline Female $(n / \%)$ & $613(53.3)$ & $205(73.0)$ & $48(36.1)$ & $192(52.0)$ & $61(49.2)$ & $99(71.7)$ & $8(7.8)$ \\
\hline Male $(n / \%)$ & $535(46.7)$ & $76(27.0)$ & $85(63.9)$ & $177(48.0)$ & $63(50.8)$ & $39(28.3)$ & $95(92.2)$ \\
\hline $\mathrm{M} \pm \mathrm{SD}$ age (yrs) & $45.6 \pm 26.23$ & $45.6 \pm 38.43$ & $45.9 \pm 30.44$ & $46.3 \pm 38.77$ & $44.5 \pm 37.40$ & $45.0 \pm 30.41$ & $42.8 \pm 23.3$ \\
\hline $\begin{array}{l}\mathrm{M} \pm \mathrm{SD} \text { work } \\
\text { experience in PE } \\
\text { teaching }(\mathrm{yrs})\end{array}$ & $17.1 \pm 10.77$ & $17.1 \pm 10.17$ & $16.9 \pm 9.85$ & $17.5 \pm 10.42$ & $16.7 \pm 10.19$ & $16.9 \pm 10.50$ & $15.7 \pm 10.48$ \\
\hline Private school & 53 & 12 & 1 & 2 & 23 & 4 & 11 \\
\hline Public school & 1079 & 263 & 132 & 363 & 100 & 129 & 92 \\
\hline Other & 16 & 6 & - & 4 & 1 & 5 & - \\
\hline Primary school & 689 & 202 & 99 & 206 & 71 & 57 & 54 \\
\hline Secondary school & 370 & 56 & 34 & 140 & 53 & 41 & 46 \\
\hline Other & 89 & 23 & - & 23 & - & 40 & 3 \\
\hline
\end{tabular}

Note. M: mean; SD: standard deviation; yrs: years.

A cross-sectional online survey study was performed between May and September 2020 and was conducted online through an electronic questionnaire, created on Google. The research team contacted PE teachers with help of In-Service Teacher Training Centres, PE online websites and forums, social media (groups dedicated to PE teachers), and through the research team's own contacts. Social media posts and emails to PE teachers included information about the survey, as well as the URL and links to access the survey. PE teachers were asked to use their computers or mobile devices to click on a link redirecting to a questionnaire on Google. The research team did not receive the names, contact information, or any other information about anyone who completed the survey. 
The only inclusion criterion was to be a professionally active PE teacher. We did not limit the study sample to other inclusion or exclusion criteria. PE teachers voluntarily and anonymously completed the online survey in their native language. The average time of completion of the questionnaires was approximately $10 \mathrm{~min}$. The study was conducted in accordance with the Declaration of Helsinki [17].

\subsection{Measures/Survey Development}

The initial survey was developed online using Google Forms Questionnaire. The survey underwent content validation by a panel of experts in the fields of PE (three academic experts from all the six countries involved in the study with university and research background in the field of PE). Experts responded to the clarity, coherence, relevance, and response options for each question. Minor changes were made based on the feedback from the experts prior to the final survey's launch. The final survey consisted of two sections: demographic information (age, gender, province, and size of the town in which the respondents worked), seniority (work experience) in the profession of a PE teacher (years), and the type of school (primary, secondary, other). Questions included in the second section concerned the subjective assessment of online teaching in PE in the times of the COVID-19 pandemic. This part of the survey comprised of 25 questions and included single- and multiple-choice questions. Several questions allowed space for optional opentext comments. It has been translated into national languages of the participating countries by the panel experts.

To evaluate the quality of implementation and PE teachers' perceived advantages, disadvantages, and encountered difficulties of online PE teaching during the first wave of the COVID-19 pandemic, only selected questions from the survey were used.

Teachers' perceived advantages, disadvantages, and encountered difficulties of online PE teaching Among the items used was the question concerning (i) advantages of online PE teaching:

1. Please rank the 3 most important advantages of online PE teaching. Assign the selected advantages to a weight of 3 to 1 , where 3 represents the most important/significant advantage of the selected three.

(1) The possibility of using modern technologies in practice;

(2) Individual approach to student learning;

(3) Greater student independence;

(4) Better relationships with students;

(5) Easier implementation of the core curriculum content related to, e.g., health education;

(6) The possibility of using interesting forms of technology to assist students to learn;

(7) An attractive and effective form of material checking;

(8) Ongoing monitoring of student results for me, parents, and students;

(9) An attractive way of presenting my competences to students.

The question was also concerning (ii) the disadvantages of online PE teaching:

2. Please rank the 3 most important disadvantages of online PE teaching. Assign selected disadvantages to a weight of 3 to 1 , where 3 represents the most important/significant disadvantage from the selected three.

(1) Limited contact with students;

(2) Inability to verify the implementation of movement tasks in a correct/proper way;

(3) Inability to monitor student progress in a satisfactory way;

(4) Lack of a personalised approach with students;

(5) More difficult implementation of the core curriculum content, related, e.g., to the area of physical development and physical fitness;

(6) More theories and less practice;

(7) Difficulties motivating students to learn/work independently.

There was also a question about (iii) difficulties on online PE teaching: 
3. Please rank the 3 biggest difficulties of online PE teaching. Assign the selected difficulties a weight from 3 to 1 , where 3 represents the most important/significant difficulty of the selected three.

(1) Lack of proper equipment at home (laptop, tablet, speakers, headphones, microphone);

(2) Lack of proper training (how to use technology);

(3) There is no experience with applications/platforms that can be used for online learning;

(4) Lack of support from the management;

(5) No or limited internet access;

(6) Problems connecting the computer/tablet/smartphone to the Internet;

(7) Lack of support from colleagues;

(8) Large class size.

After each of the above-mentioned questions was a place where participants could enter other advantages/barriers or difficulties not mentioned in the survey. The openended answers of the study participants are presented in the Supplementary Materials (Tables S1-S3).

The reliability of the selected questions of the survey was verified by calculating Cronbach's alpha coefficient. Cronbach's alpha coefficient for advantages were $\alpha=0.94$, $\alpha=0.95$ for the negative consequences, and $\alpha=0.84$ for the biggest difficulties.

Assessment of online PE teaching

Teachers assessed online PE teaching by answering the question:

1. How do you generally assess the current online PE teaching (implementation and technical possibilities of your school)?

(1) very weak;

(2) poorly;

(3) on average;

(4) well;

(5) very good.

Teachers' concerns about online learning

To obtain teachers' biggest concerns about online learning we have asked:

1. What are your biggest concerns about online learning? It was a multiple-choice question with answers:

(1) I have no worries;

(2) Student safety (injury, accidents);

(3) My image will be used for non-essential/not didactic purposes;

(4) Using Internet applications is difficult;

(5) During the recording/transmission I will make a mistake;

(6) Materials that are my intellectual property will be visible on the Internet without my consent and knowledge.

After the above-mentioned question was a place where participants could enter their own concerns not mentioned in the survey.

Teachers' assessment of student online activity

We asked PE teachers about their students' online activity:

1. Do you think that online activity of students in comparison to traditional classes carried out at school was.

(1) Higher,

(2) Same;

(3) Lower.

Teachers' satisfaction with self-fulfilment in the profession and attitude to work

Teachers' satisfaction with self-fulfilment in the profession and attitude to work was assessed by using two single choice questions:

1. Has the change in the form of the implementation of PE classes affected your satisfaction with self-fulfilment in the profession? 
(1) Yes, I see a significant change for the better;

(2) I didn't notice a change in this aspect;

(3) Yes, I see a significant change for the worse.

2. Has the implementation of professional tasks in the form of online teaching changed your attitude to work?

(1) I feel increased motivation and commitment;

(2) I don't see any change;

(3) Yes, I feel reduced motivation and commitment.

Teachers' goal while teaching PE online

Teachers' profession and goals while online teaching were assessed by using a multiple choice question:

1. When teaching online PE, my goal is.

(1) Encouraging students to promote healthy behavior;

(2) Supporting students in their needs related to physical activity and health;

(3) Raising students' awareness of the importance of health behaviors;

(4) Supporting students in maintaining their physical fitness in difficult conditions;

(5) Supporting students in coping with stress;

(6) Finding ways to implement the core curriculum and to implement it.

In addition, after the above-mentioned question was a place where participants could enter their own answers not mentioned in the survey.

\subsection{Data Analysis}

Microsoft Excel and Statistica 13.0 software (StatSoft, Krakow, Poland).were used for data analysis. Data from the six countries were pooled after cleaning. Descriptive statistics were used to describe the PE teachers' characteristics (means \pm standard deviations, percentage values). Percentage values have been used in all the questions with singlechoice answers. In all questions based on the ranking hierarchy strategy (e.g., advantages, disadvantages, naming the ranking of the difficulties), where the respondents were asked to provide three choices ranked, the ranking was based on accordingly to the following procedure: 3 points were given to the most significant item (variable) and 1 point to the least significant one.

Due to the lack of normal distribution of data, statistical analyses on the base of sum of ranks were carried out with the use of Kruskal-Wallis test, employing post-hoc Dunn's pairwise test where applicable, with the $p$ level set at 0.05 .

\section{Results}

An overall look at the general findings' statistics allowed for some observations. We found that more than twice as many ( $43.9 \%$ vs. $20.8 \%)$ PE teachers assessed their online PE teaching routine in times of the first wave of a COVID-19 pandemic as well (30.2\%) or very good (13.7\%) vs. poorly (13.24\%) and very weak $(7.6 \%)$. "On average" was declared by $35.3 \%$ of the respondents. Analysing the results in detail for individual countries, we can say that a clear advantage of positive evaluations over negative ones occurred in Croatia (61.2\% vs. $10.6 \%)$, Poland ( $42.4 \%$ vs. $19.2 \%)$, Bulgaria $(48.6 \%$ vs. $23.2 \%)$, and in Turkey (36.3\% vs. $26.6 \%)$. However, in Kosovo (13.6\% vs. $30.1 \%$ ) and in Macedonia $(24.8 \%$ vs. $37.6 \%)$, it is the other way round. In both countries, the score for "on average" was also high at $56.3 \%$ and $37.6 \%$, respectively. It is important to add that, in Macedonia, none of the respondents marked the answer "very good".

In the evaluation of the most important advantages of online PE teaching (Table 2) Kruskal-Wallis analysis indicated statistically significance differences in variable 1 concerning possibilities of using modern technology in practice, both at the primary and secondary school level. Among primary school PE teachers, the differences of opinions were significant $(p<0.05)$ between Polish and Macedonian teachers (with Polish teachers scoring higher), and Macedonian and Croatian ones (with Macedonian teachers scoring higher), 
whereas, at the secondary school level, Polish PE teachers assessed those possibilities higher than teachers from all other countries $(p<0.05)$.

Table 2. Comparison (sum of ranks) of the most important advantages of online PE separately for primary and secondary PE teachers and in each country.

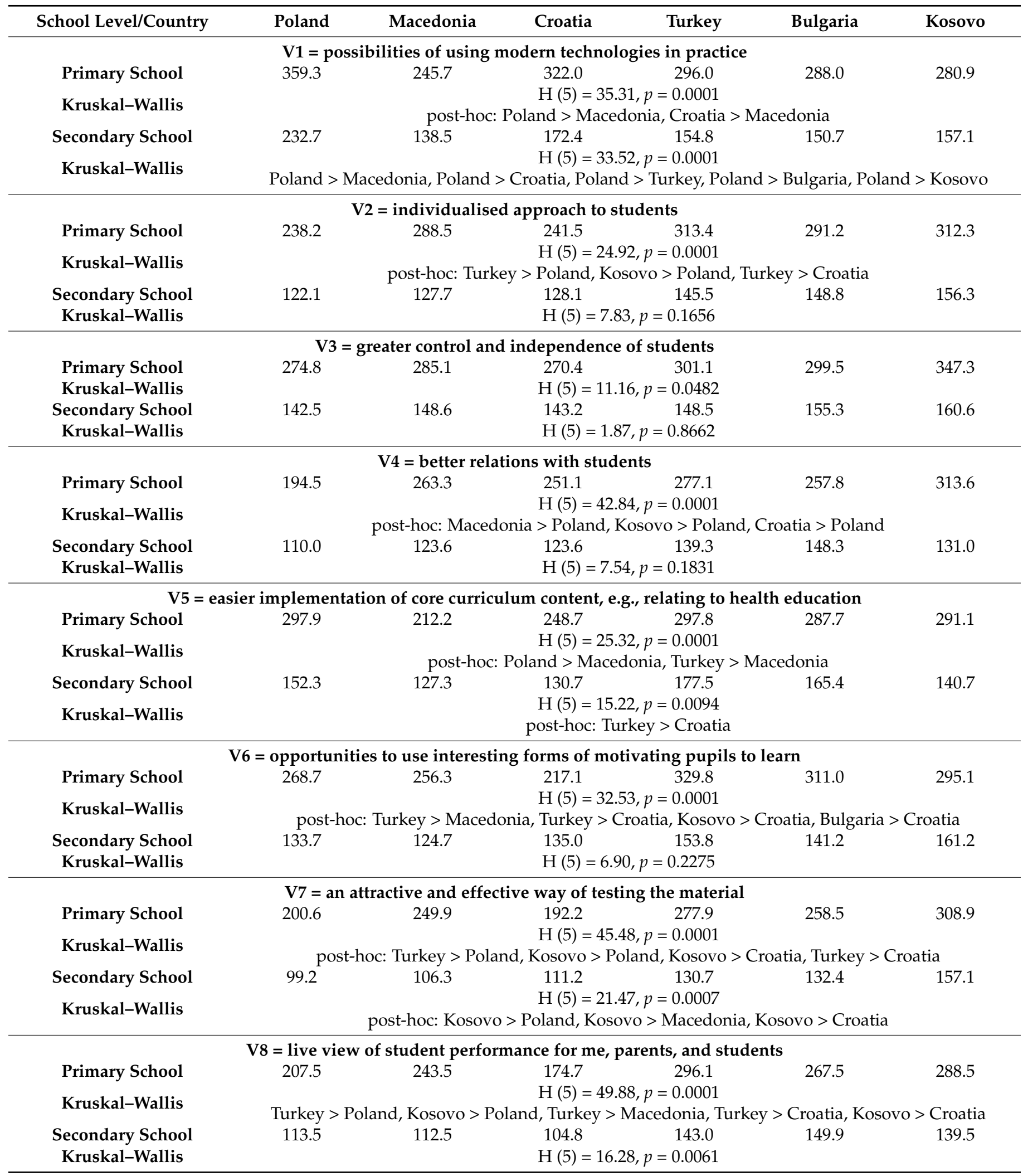


Table 2. Cont.

\begin{tabular}{|c|c|c|c|c|c|c|}
\hline School Level/Country & Poland & Macedonia & Croatia & Turkey & Bulgaria & Kosovo \\
\hline \multicolumn{7}{|c|}{ V9 = an attractive way of presenting my competences to the students } \\
\hline Primary School & 262.5 & 281.0 & 236.3 & 282.6 & 241.6 & 285.5 \\
\hline Kruskal-Wallis & & & $\mathrm{H}(5)=$ & $=0.1088$ & & \\
\hline $\begin{array}{l}\text { Secondary School } \\
\text { Kruskal-Wallis }\end{array}$ & 124.7 & 128.0 & $\begin{array}{l}126.2 \\
H(5)=\end{array}$ & $\begin{array}{r}135.3 \\
=0.1627\end{array}$ & 155.6 & 154.8 \\
\hline
\end{tabular}

In the case of an individualised approach to students (variable 2), the Kruskal-Wallis test was significant only among primary school PE teachers, especially between those from Poland $>$ Turkey, Poland $>$ Kosovo, as well as Turkey $>$ Croatia $(p<0.05)$. There were no such differences in the evaluation of this item of online teaching among secondary school PE teachers. There were also no significant differences worth noticing in variable 3 on the control and independence of students. PE teachers at both levels had a similar estimation of the situation in their countries. However, in judging the relations with students (variable 4), differences occurred between primary school PE teachers from Poland and Macedonia, Kosovo, and Croatia, with Polish teachers considering this situation as worse in all cases $(p<0.05)$. There were differences in the assessment of dealing with the implementation of the core curriculum's contents, especially those related to health education (variable 5) between PE teachers from examined countries. At the primary school level, PE teachers from Poland scored higher than those from Macedonia $(p<0.05)$, and Macedonian teachers obtained worse scores than those from Turkey $(p<0.05)$. At the secondary school teaching level, it was only significant between Turkish and Croatian PE teachers, with Turkish teachers scoring higher $(p<0.05)$. Variable 6 on the assessment of opportunities to use interesting forms of motivating pupils to learn showed no big differences in opinions neither at primary nor secondary school levels among teachers from the examined countries.

In terms of the evaluation of the opportunities to use attractive testing materials (variable 7) at the primary school level, differences were statistically significant between $\mathrm{PE}$ teachers from Poland $<$ Turkey $(p<0.05)$ and Kosovo $>$ Poland $(p<0.05)$, Kosovo $>$ Croatia $(p<0.05)$, and Turkey $>$ Croatia $(p<0.05)$. In the case of the evaluation of the live view of student performance (variable 8), differences between Turkey $>$ Poland $(p<0.05)$, Kosovo $>$ Poland $(p<0.05)$, Turkey $>$ Macedonia $(p<0.05)$, Turkey $>$ Croatia $(p<0.05)$, and Kosovo $>$ Croatia $(p<0.05)$ were significant at the primary school level. There were no statistically significant differences between PE teachers from the examined countries at the secondary school level (despite significant Kruskal-Wallis). There were no statistical differences between the countries at either of the education levels in variable 9 evaluating advantages of attractive new way of presenting PE teacher's competences to the students. All the teachers at each level evaluated this item equally.

In the evaluation of the most important negative consequences of online PE teaching (Table 3), the Kruskal-Wallis analysis indicated a statistical significance of differences in variable 1 on the estimation of the situation with limited contacts with pupils between PE teachers from Poland $>$ Kosovo $(p<0.05)$ at the primary education level, whereas it was between Polish teachers scoring higher than those from Kosovo, Croatian scoring higher than Kosovars $(p<0.05)$, and Bulgarians scoring higher than Kosovars, as well $(p<0.05)$, at the secondary level. In variable 2 concerning the lack of control over the teaching/learning process, PE teachers from primary schools of Poland scored higher than those from Kosovo $(p<0.05)$, those from Croatia scored higher than those from Kosovo $(p<0.05)$, and those from Bulgaria scored higher than those from Kosovo $(p<0.05)$. In the case of secondary school PE teachers, the differences were noticed in Poland $>$ Turkey $(p<0.05)$, Poland $>$ Kosovo $(p<0.05)$, Croatia $>$ Turkey $(p<0.05)$, Croatia $>$ Kosovo, and Bulgaria $>$ Kosovo $(p<0.05)$, indicating a variety of opinions in this matter. Variable 3, on the limited chances of monitoring the progress of the pupils, showed differences of opinions between primary school PE teachers from Poland $>$ Kosovo $(p<0.05)$ and 
Macedonia $>$ Kosovo $(p<0.05)$, whereas, at the secondary level of education, it was between PE teachers from Poland $>$ Kosovo $(p<0.05)$. On the chances for individualised teaching (variable 4), primary school PE teachers from Poland had lower opinions than the ones from Macedonia $(p<0.05)$, and those from Macedonia had higher opinions than those from Bulgaria $(p<0.05)$. Apparently, at the secondary school level, despite the fact that the Kruskal-Wallis test indicated a significance, no statistically important differentiation in post-hoc testing was noticed. In terms of the difficulties of following PE curricula (variable 5), opinions differed between the PE teachers from the examined countries at both levels. In primary schools, Polish teachers scored higher than the ones from Macedonia $(p<0.05)$, Croatia $(p<0.05)$, Bulgaria $(p<0.05)$, and Kosovo $(p<0.05)$, whereas, at the secondary level, the differences were noticed between Poland $>$ Turkey $(p<0.05)$, Bulgaria $>$ Turkey $(p<0.05)$, and Bulgaria $>$ Kosovo $(p<0.05)$. Assessing the problems with delivering more theory than practice (variable 6) showed no differentiation of opinion at either of the educational levels. A similar situation was acknowledged in the case of variable 7 on assessing difficulties with motivating process.

Table 3. Comparison (sum of ranks) of the most important negative consequences of online PE separately for primary and secondary PE teachers and in each country.

\begin{tabular}{|c|c|c|c|c|c|c|}
\hline $\begin{array}{l}\text { School Level/ } \\
\text { Country }\end{array}$ & Poland & Macedonia & Croatia & Turkey & Bulgaria & Kosovo \\
\hline \multicolumn{7}{|c|}{ V1 = limited contact with the pupils } \\
\hline Primary School & 310.3 & 295.5 & 254.3 & 269.2 & 292.6 & 223.3 \\
\hline Kruskal-Wallis & \multicolumn{6}{|c|}{$\begin{aligned} & \mathrm{H}(5)=22.57, p=0.0004 \\
& \text { post-hoc: Poland }>\text { Kosovo }\end{aligned}$} \\
\hline Secondary School & 162.9 & 142.1 & 162.8 & 122.8 & 170.2 & 108.0 \\
\hline Kruskal-Wallis & \multicolumn{6}{|c|}{$\begin{array}{c}\mathrm{H}(5)=26.02, p=0.0001 \\
\text { Post-hoc: Poland }>\text { Kosovo, Croatia }>\text { Kosovo, Bulgaria }>\text { Kosovo }\end{array}$} \\
\hline \multicolumn{7}{|c|}{ V2 = lack of control over the teaching/learning process } \\
\hline Primary School & 339.0 & 287.2 & 309.0 & 267.8 & 320.5 & 207.3 \\
\hline Kruskal-Wallis & \multicolumn{6}{|c|}{$\begin{array}{c}\mathrm{H}(5)=40.76, p=0.0001 \\
\text { post-hoc: Poland }>\text { Kosovo, Croatia }>\text { Kosovo, Bulgaria }>\text { Kosovo }\end{array}$} \\
\hline Secondary School & 198.0 & 166.5 & 182.6 & 132.3 & 191.5 & 115.8 \\
\hline Kruskal-Wallis & \multicolumn{6}{|c|}{$\begin{array}{c}\mathrm{H}(5)=38.68, p=0.0001 \\
\text { ph:Poland }>\text { Turkey, Poland }>\text { Kosovo, Croatia }>\text { Turkey, Croatia }>\text { Kosovo, Bulgaria }>\text { Kosovo }\end{array}$} \\
\hline \multicolumn{7}{|c|}{ V3 = limited chances of monitoring the progress of the pupils } \\
\hline Primary School & 290.0 & 303.4 & 270.1 & 270.1 & 290.2 & 213.0 \\
\hline Kruskal-Wallis & \multicolumn{6}{|c|}{$\mathrm{H}(5)=15.49, p=0.0085$} \\
\hline Secondary School & 174.7 & 165.9 & 136.6 & 134.6 & 177.4 & 120.9 \\
\hline Kruskal-Wallis & \multicolumn{6}{|c|}{$\begin{aligned} & \mathrm{H}(5)=20.08, p=0.0012 \\
& \text { post-hoc: Poland }>\text { Kosovo }\end{aligned}$} \\
\hline \multicolumn{7}{|c|}{ V4 = limited chanced for individualised teaching } \\
\hline Primary School & 230.0 & 308.8 & 252.4 & 279.3 & 223.3 & 242.8 \\
\hline Kruskal-Wallis & \multicolumn{6}{|c|}{ 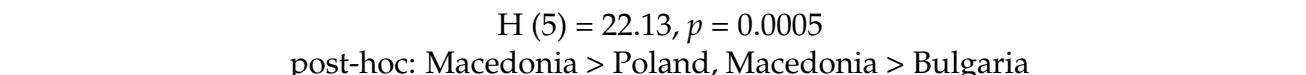 } \\
\hline Secondary School & 116.8 & 128.5 & 148.2 & 154.5 & 125.3 & 115.2 \\
\hline Kruskal-Wallis & \multicolumn{6}{|c|}{$\mathrm{H}(5)=12.73, p=0.0260$} \\
\hline \multicolumn{7}{|c|}{ V5 = difficult to follow PE curricula (specifically concerning physical development and fitness) } \\
\hline Primary School & 312.8 & 301.5 & 298.6 & 269.2 & 337.3 & 205.3 \\
\hline Kruskal-Wallis & \multicolumn{6}{|c|}{$\begin{array}{l}H(5)=27.49, p=0.0001 \\
\text { post-hoc: Poland }>\text { Macedonia, Poland }>\text { Croatia, Poland }>\text { Kosovo, Bulgaria }>\text { Poland }\end{array}$} \\
\hline Secondary School & 173.4 & 158.8 & 162.8 & 119.9 & 203.2 & 121.2 \\
\hline Kruskal-Wallis & \multicolumn{6}{|c|}{$\begin{array}{c}H(5)=33.99, p=0.0001 \\
\text { post-hoc: Poland }>\text { Turkey, Bulgaria }>\text { Turkey, Bulgaria }>\text { Kosovo }\end{array}$} \\
\hline
\end{tabular}


Table 3. Cont.

\begin{tabular}{|c|c|c|c|c|c|c|}
\hline $\begin{array}{l}\text { School Level/ } \\
\text { Country }\end{array}$ & Poland & Macedonia & Croatia & Turkey & Bulgaria & Kosovo \\
\hline \multicolumn{7}{|c|}{ V6 $=$ more theory than practice } \\
\hline Primary School & 284.0 & 277.1 & 266.8 & 269.9 & 307.0 & 244.1 \\
\hline Kruskal-Wallis & \multicolumn{6}{|c|}{$\mathrm{H}(5)=6.06, p=0.2995$} \\
\hline Secondary School & 157.1 & 149.7 & 159.6 & 155.3 & 187.4 & 138.7 \\
\hline Kruskal-Wallis & \multicolumn{6}{|c|}{$\mathrm{H}(5)=7.35, p=0.1954$} \\
\hline \multicolumn{7}{|c|}{ V7 $=$ more difficult motivating process } \\
\hline Primary School & 275.4 & 292.8 & 255.1 & 289.5 & 283.1 & 234.7 \\
\hline Kruskal-Wallis & \multicolumn{6}{|c|}{$\mathrm{H}(5)=8.15, p=0.1481$} \\
\hline Secondary School & 147.6 & 137.6 & 157.2 & 153.7 & 150.0 & 128.7 \\
\hline Kruskal-Wallis & \multicolumn{6}{|c|}{$\mathrm{H}(5)=4.50, p=0.4788$} \\
\hline
\end{tabular}

In the evaluation of the biggest difficulties of online PE teaching (Table 4), the KruskalWallis analysis indicated a statistical significance in the differences in variable 1 , on the lack of proper equipment at home (i.e., no laptops, tables, speakers, microphones), with Polish PE primary teachers gaining the lowest scores, statistically lower than teachers from Turkey $(p<0.05)$ and Kosovo $(p<0.05)$. Turkish teachers, who obtained the highest score in this item, also marked it as more difficult than Croatian teachers $(p<0.05)$. No differences were noticed among the opinions of PE teachers at the secondary school level in this issue. The lack of proper training on the use of technology (variable 2) did not indicate statistically significant differences at either of the education levels. Such was the case with the item about experience with applications/platforms that can be used for online learning (variable 3). None of the teacher groups from the examined countries saw that as a problem bigger than their teaching peers from other countries. The lack of support from the management (variable 4 ) was seen as an issue with Croatian primary school PE teachers, feeling less supported than teachers from other countries, but it was statistically significant with the score of Kosovar teachers $(p<0.05)$. No differences, though, were found in secondary school education between the answers of PE teachers from various countries.

Table 4. Comparison (sum of ranks) of the biggest difficulties of online PE separately for primary and secondary PE teachers and in each country.

\begin{tabular}{|c|c|c|c|c|c|c|}
\hline $\begin{array}{l}\text { School Level/ } \\
\text { Country }\end{array}$ & Poland & Macedonia & Croatia & Turkey & Bulgaria & Kosovo \\
\hline \multicolumn{7}{|c|}{ V1 = lack of proper equipment at home (laptop, tablet, speakers, headphones, microphone) } \\
\hline Primary School & 247.4 & 292.4 & 249.6 & 323.2 & 287.0 & 325.2 \\
\hline Kruskal-Wallis & \multicolumn{6}{|c|}{$\begin{aligned} & \mathrm{H}(5)=24.72, p=0.0002 \\
& \text { post-hoc: } \text { Turkey }>\text { Poland, Kosovo }>\text { Poland, Turkey }>\text { Croatia }\end{aligned}$} \\
\hline Secondary School & 145.6 & 159.3 & 130.4 & 134.0 & 143.5 & 118.4 \\
\hline Kruskal-Wallis & \multicolumn{6}{|c|}{$\mathrm{H}(5)=7.00, p=0.2200$} \\
\hline \multicolumn{7}{|c|}{ V2 = lack of proper training (how to use technology) } \\
\hline $\begin{array}{l}\text { Primary School } \\
\text { Kruska-Wallis }\end{array}$ & 269.3 & 326.0 & 281.1 & $\begin{array}{r}313.3 \\
0.0769\end{array}$ & 301.9 & 298.3 \\
\hline $\begin{array}{l}\text { Secondary School } \\
\text { Kruskal-Wallis }\end{array}$ & 159.9 & 170.8 & $\begin{array}{l}140.3 \\
H(5)=\end{array}$ & $\begin{array}{r}149.2 \\
0.1051\end{array}$ & 148.9 & 121.4 \\
\hline \multicolumn{7}{|c|}{ V3 = no experience with applications/platforms that can be used for online learning } \\
\hline Primary School & 291.5 & 325.6 & 274.0 & 292.5 & 284.4 & 282.2 \\
\hline Kruskal-Wallis & & & $\mathrm{H}(5)=$ & 0.2783 & & \\
\hline $\begin{array}{l}\text { Secondary School } \\
\text { Kruskal-Wallis }\end{array}$ & 161.0 & 152.7 & $\begin{array}{l}151.0 \\
\mathrm{H}(5)=\end{array}$ & $\begin{array}{r}138.5 \\
0.5342\end{array}$ & 147.0 & 131.0 \\
\hline
\end{tabular}


Table 4. Cont.

\begin{tabular}{|c|c|c|c|c|c|c|}
\hline $\begin{array}{l}\text { School Level/ } \\
\text { Country }\end{array}$ & Poland & Macedonia & Croatia & Turkey & Bulgaria & Kosovo \\
\hline \multicolumn{7}{|c|}{ V4 = lack of support from the management } \\
\hline Primary School & 211.9 & 230.4 & 185.7 & 249.2 & 225.4 & 271.1 \\
\hline Kruskal-Wallis & \multicolumn{6}{|c|}{$\begin{array}{c}\mathrm{H}(5)=18.05, p=0.0029 \\
\text { post-hoc: Kosovo }>\text { Croatia }\end{array}$} \\
\hline Secondary School & 109.0 & 94.8 & 104.9 & 130.8 & 109.5 & 117.5 \\
\hline Kruskal-Wallis & \multicolumn{6}{|c|}{$\mathrm{H}(5)=8.33, p=0.1386$} \\
\hline \multicolumn{7}{|c|}{ V5 $=$ no or limited Internet access } \\
\hline Primary School & 224.9 & 181.0 & 276.4 & 283.5 & 243.5 & 290.4 \\
\hline Kruskal-Wallis & \multicolumn{6}{|c|}{$\begin{aligned} & H(5)=37.70, p=0.0001 \\
& \text { post-hoc: } \text { Croatia }>\text { Macedonia, Turkey }>\text { Macedonia, Kosovo }>\text { Macedonia }\end{aligned}$} \\
\hline Secondary School & 126.0 & 125.3 & 126.0 & 130.7 & 124.4 & 110.9 \\
\hline Kruskal-Wallis & \multicolumn{6}{|c|}{$\mathrm{H}(5)=2.05, p=0.8412$} \\
\hline \multicolumn{7}{|c|}{ V6 $=$ problems connecting the computer/tablet/smartphone to the Internet } \\
\hline Primary School & 172.3 & 206.1 & 277.3 & 300.1 & 249.7 & 299.0 \\
\hline Kruskal-Wallis & \multicolumn{6}{|c|}{$\begin{array}{c}\text { post-hoc: Croatia }>\text { Poland, Turkey }>\text { Poland, Bulgaria }>\text { Poland, Kosovo }>\text { Poland, } \\
\text { Croatia }>\text { Macedonia, Turkey }>\text { Macedonia, Kosovo }>\text { Macedonia }\end{array}$} \\
\hline Secondary School & 98.0 & 120.8 & 133.5 & 129.5 & 119.0 & 125.1 \\
\hline Kruskal-Wallis & \multicolumn{6}{|c|}{$\mathrm{H}(5)=7.95, p=0.1589$} \\
\hline \multicolumn{7}{|c|}{ V7 = lack of support from colleagues } \\
\hline Primary School & 153.9 & 130.0 & 127.3 & 157.5 & 150.6 & 175.2 \\
\hline Kruskal-Wallis & \multicolumn{6}{|c|}{$\mathrm{H}(5)=14.66, p=0.0119$} \\
\hline Secondary School & 96.0 & 76.2 & 87.3 & 101.7 & 93.5 & 111.6 \\
\hline Kruskal-Wallis & \multicolumn{6}{|c|}{$\mathrm{H}(5)=10.15, p=0.0710$} \\
\hline \multicolumn{7}{|c|}{ V8 = large class size } \\
\hline Primary School & 153.6 & 192.9 & 169.3 & 169.9 & 182.5 & 190.9 \\
\hline Kruskal-Wallis & \multicolumn{6}{|c|}{$\mathrm{H}(5)=4.77, p=0.4442$} \\
\hline Secondary School & 98.8 & 115.2 & 105.5 & 102.6 & 109.0 & 125.6 \\
\hline Kruskal-Wallis & \multicolumn{6}{|c|}{$\mathrm{H}(5)=5.03, p=0.4120$} \\
\hline
\end{tabular}

Limited access to the Internet (variable 5) was seen as a problem for PE primary school teachers from Macedonia, who obtained the lowest score, significantly lower than those from Croatia $(p<0.05)$, Turkey $(p<0.05)$, and Kosovo $(p<0.05)$. No differences were observed at the level of secondary education. Variable 6, on estimating problems with connecting the computer/tablet/smartphone to the Internet, showed some differences of opinions among primary school PE teachers. Teachers from Poland assessed this as a lower problem than teachers from Croatia, Turkey, Bulgaria, and Kosovo (all $p<0.05$ ). In addition, teachers from Macedonia assessed it lower than those from Croatia, Turkey, and Kosovo (all $p<0.05$ ). However, there were no meaningful differences of opinions at the level of secondary education. In terms of the lack of support from colleagues (variable 7), interestingly, there were no differences (despite significant Kruskal-Wallis results) at either of the education levels. Similarly, no statistically significant differences occurred between PE teachers of the examined countries at any of the educational levels in terms of variable 8 concerning the size of the class.

As for the biggest concerns about online learning, however, the majority of PE teachers had concerns about students' safety (injury, accidents) (41.6\%). The second on the ranking priorities was the variable about the use of the materials. The teachers felt that their intellectual property will be visible on the Internet without their consent and knowledge $(26.9 \%)$, and they feared that their image will be used for purposes other than essential/nonteaching $(26.0 \%)$.

Concerns about the safety of students and the epidemiological situation itself caused their modifications of the curriculum content. While teaching online, PE teachers focused 
mainly on the following objectives: encouraging students to promote healthy behaviour $(51.1 \%)$, supporting students in their needs related to physical activity and health $(49.1 \%)$, raising students' awareness of the importance of health behaviours (47.0\%), and supporting students in maintaining their physical fitness in difficult conditions (47.0\%). The clear focus on raising awareness of the importance of health promotion of PA is probably the result of teachers' concern for the general health of their pupils, endangered not only by increased sedentary activity due to distance learning but also the desire to strengthen the general immunity of the body during the adverse health conditions of the COVID-19 pandemic by advocating for regular physical activity and demonstrating its vital importance for health.

Concluding the analysis of online teaching, it is worth summarising with an evaluation of activities of both students and PE teachers. Moreover, $72.6 \%$ of PE teachers consider that the activity of students in pandemic times in comparison to traditional classes carried out at school is lower. In all countries, the indications of this in terms of the results in this area were similar, ranging from $79.7 \%$ (highest score, Macedonia) to $66.1 \%$ (lowest score, Turkey). Only $7.6 \%$ of PE teachers considered that the activity of students might have been higher in the examined lockdown period.

The transition from the traditional form of delivery of the PE curricula contents to online teaching has also affected teachers' activity. The change for the worse in terms of the satisfaction with self-fulfilment in the profession was felt by $39.6 \%$ respondents, which decreased motivation and commitment at work by $35.2 \%$ of respondents. Turkish $(46.8 \%)$ and Bulgarian (43.5\%) PE teachers were the most demotivated. A change for the better has been seen in themselves by only $19.3 \%$ teachers, yet increased motivation and commitment at work was felt by only one fifth of those respondents (27.9\%), mostly among Kosovar (44.7\%) and Macedonian (36.8\%) PE teachers.

\section{Discussion}

The COVID-19 pandemic has tested the traditional patterns of everyday living of people around the world. It has completely changed the educational systems in European countries, including PE and sport classes. PE and sports training have been transformed into distance and online education and training [18]. The physical activity of students of all educational levels was significantly reduced. This point of view has already been indicated in different research reports related to the problem $[8,19,20]$.

The present study examined the PE teachers' opinion about the online teaching process during the first wave of the COVID-19 pandemic from six European countries-Poland, Croatia, Bulgaria, North Macedonia, Turkey, and Kosovo. The purpose of this study was to evaluate the quality of implementation and PE teachers' evaluation of the most important advantages, disadvantages, and difficulties of online PE teaching. All teachers were qualified to teach PE and taught the subject at the primary or secondary school levels. In the majority of the countries included in the study, to teach PE in primary schools ( 7-10 years), teachers need to be qualified as primary school teachers. Macedonia and Poland allow specialised PE teachers to conduct PE lessons [21]. PE in post-primary schools is taught by specialised PE teachers in all the studied countries.

The sample included teachers from different age groups and with different pedagogical experiences. The majority of teachers included in the sample are working in public schools. Before the pandemic, there had been some differences between the included countries. These differences referred to time allocated for PE classes (up to $140 \mathrm{~min}$ per week in Bulgaria, Croatia, Kosovo, and Macedonia and to 180-200 min per week for primary education in Poland and Turkey), teachers responsible for PE classes, etc. A similar situation with time allocation of PE classes is noted for post-primary schools. In the period of the first wave of the pandemic, in addition to transferring to online teaching, other changes in the teaching process occurred as well. Namely, the time allocation for online classes, including PE classes, changed in nearly all countries included in the study. For example, in Poland, Macedonia, and Bulgaria, online classes were shortened by 10-15 min, depending on the country and the grade of the students. Additionally, other changes also 
occurred. For example, in Macedonia, teachers were suggested to organise PE classes once a week, instead of three times per week, outside with extended duration. In Croatia, educational programmes for each grade were created and broadcasted on national education information networks. Similar changes were noted in other countries as well.

The results of the research showed that the problems of online PE teaching were assessed differently by teachers from the examined countries. A positive approach to online PE teaching in some countries (Poland, Croatia, and Bulgaria) collided with the more negative evaluation by the teachers in other ones (Turkey, North Macedonia, Kosovo). Such a result is due to several factors including previous experience with technology implemented in PE classes, specific national approaches to online teaching, as well as in different approaches in conducting online PE teaching during the first few months of pandemic, when the study was conducted. Namely, before the pandemic, reforms in the educational systems and especially in PE were happening in several counties including Poland, Croatia, Bulgaria, and Macedonia. With the national reform that is ongoing in Croatia since 2017, the educational system is reforming to be objective-based and goal-oriented. Reform activities require teachers to participate in many online lectures, workshops, and activities. These may explain the positive attitude of Croatian teachers to online PE teaching. A similar situation is noted for Poland and Bulgaria. In comparation to this, in Macedonia, the reform from 2016 required the use of technology in 30\% of the curricula in all subjects, including PE as well. This was not well accepted by PE teachers, because it was not followed with specific guidance and instructions. We assume that this negative attitude also has its implications to the negative approach regarding online PE teaching. Another aspect is the support during the pandemic for online teaching. In Poland, Bulgaria, and Croatia, distance learning was supported by the Ministry of Education and Science and the relevant educational institutions that offered specific online educational platforms for training and teaching in this area. PE teachers were also supported by their school authorities and/or teachers associations. In many countries, this was also supplemented with online classes broadcasted on national TV. This was the case in Croatia and Turkey. Apparently, such support from relevant educational institutions was not provided for PE teachers in Macedonia and Kosovo, creating a feeling that teachers were left on their own. In North Macedonia, in the period when the study was conducted, there were no clear instructions for online teaching and no suggestions for any unified platform that ought to be used. In Macedonia, some positive individual initiatives from teachers and schools were noted, but it was rather down to some individual incidents, not a country-wide initiative. This is clearly reflected in the result, where, in Macedonia, none of the respondents marked the answer "very good", and when analysing teachers' answers for advantages and disadvantages of online teaching, it was noted that most of the respondents supplemented their answers with comments that "online teaching is only improvisation", "face-to-face communication, group work and interaction is the essence of PE classes", "doing it online, PE classes lose the essence", "there is no advantage of online PE teaching". In Kosovo, the activity of teachers and their skills in finding innovative approaches to conducting online PE education were relied on. Another reason for the difference in the responses may be the different cultural, social, and demographic characteristics of the teachers in the studied countries. Particularly, possible reasons can be identified in the working experiences of the teachers, the level of their IT skills, preparedness, and flexibility to apply new technologies, but also technical facilities that the teachers have at their disposal (computer, access to the Internet, good Internet connection, etc.). These elements can vary not just from country to country but also from different places within one country (urban and rural setting). Interestingly, difficulties in distance PE teaching were also reported by teachers in other countries, such as Norway [6] and Spain [7]. Difficulties in Norway were in the lack of competences for online teaching, the lower priority of the subject, issues related to the monitoring and control over children during PE classes, dependence on parents, and home circumstances [6]. Another group of difficulties is more related to teachers' personal feelings during online teaching. According to Varea et al. [7], these include: less enjoyment, lower motivation for work, 
missing the personal contacts, feeling sad and depressed, etc. Furthermore, in the study that Varea et al. [7] conducted on a sample of pre-service teachers in Spain, it was reported that PE teachers miss their physical activity and direct contact with students as well. Their concerns are related to the teaching of a 'hands on' subject, such as PE, through digital technologies [7].

The most significant advantage of the online PE teaching named by all the examined teachers was the "possibility for using modern technology in practice". This advantage was reported by the respondents for the teaching of PE in the primary and secondary schools. It is noteworthy that Polish teachers scored higher on this variable on the advantages in the secondary level as compared to teachers from all other countries. This can be due to the support that Polish teachers receive from PE teachers' associations as well as a wellestablished system of teacher support before the pandemic. Another possible reason is the frequent use of technology in their teaching practice before the pandemic, which provides an easier transfer to online teaching. Namely, in 2017, the Polish National PE curriculum was enriched by modern technology-PE teachers are expected to equip pupils with the knowledge and skills for using activity trackers, mobile phone applications dealing with physical activity, etc. In this regard, different workshops were conducted to support PE teachers about the use of new technologies. Therefore, most of them probably were familiar with new technology issues, especially those working in the secondary level and primary level (from classes 5-8). In addition, the possibility for using modern technology in practice with students from secondary schools is understandable and expected considering that secondary school children are the $\mathrm{Z}$ generation or the generation that is closely related to technology and has experience in its use. Easier transfer to online teaching in secondary school compared to primary school was also confirmed in the results from other countries in the study.

In online education for pupils, the most significant advantages that were pointed out by the teachers seem to be: an attractive form of demonstrating competences in front of pupils, a real-time overview of the pupils' performance for both the teacher and the parents and pupils, and more control and independence for the pupils. The possibility to monitor movement performance of the pupils is also important for establishing a good teacher-pupil relationship. There is also another advantage: parents can also observe their children practicing in real time. Undoubtedly, the organisation, characteristics, and specific appearance of the online education in different countries influence the evaluation of its positive aspects by teachers.

To some extent, this can be explained with the range of skills of students in using technology and their efficiency.

Children and adolescents have a natural interest to use technology and various sorts of digital applications as a tool to improve their movement habits. This has been confirmed in numerous studies, reporting that interactive video games, a variety of mobile applications, and internet-based PA interventions stimulate children's interest for physical activity and promote their participation in active lifestyles [22,23]. If applied correctly, technology can be interactive, fun, and can boost movement and physical activity [24]. If used in a proper manner, by selecting online platforms, mobile applications, and even video games that are movement-based and familiar for the children, the reported benefits can facilitate the process of online PE teaching during the pandemic and make it easier and more effective.

The difference in teachers' assessments of the "individual approach to students" indicator in primary education is probably due to the different experiences of the respondents in working with the youngest students.

It should be emphasised that the control and independence of students in the context of online education is considered to be a major advantage of equal importance for all teachers in both levels of education.

PE teachers from all countries are convinced that online teaching offers various forms and approaches to motivate students to acquire new knowledge and skills in the subject. 
The differences in teachers' responses to the use of primary school tests in online teaching are probably due to the different experiences of sports teachers in separate countries in applying this type of learning material.

When speaking about the advantages of online PE teaching, the greater benefits of online teaching have been reported by teachers in the secondary school level. Teachers from Poland, Bulgaria, and Kosovo generally rated these benefits at a similar level for both primary and secondary school. In contrast, teachers from Macedonia, Croatia, and Turkey rated the benefits of online teaching significantly higher in secondary school than in primary school. Considering that different teachers work at different levels of education, we assume that the obtained differences are due to personal experiences of the teachers and are not country related.

The biggest disadvantage of this type of training seemed to be the reduced motor activity of students. This result coincides with other studies on a similar problem $[8,25]$. They have also shown that they have been presented with a new work experience in organising distance learning [26]. At the same time, PE teachers pointed out the significant negative consequences of online PE for primary and secondary schools. In the first place, they named the limited contact with pupils and the lack of control on the quality of the teaching/learning process. The differences in the interpretation of these two disadvantages by teachers from Poland, Croatia, and Bulgaria compared to teachers in Kosovo are, in our view, due to some specific social and cultural characteristics as well as the personal experience of teachers.

This finding is logical given the fact that distance learning lacks direct contact with pupils. At the same time, the control over the activity of the pupils is lowered and there is not always effective feedback. It is difficult to track and manage the development of each child individually.

The results extracted from the qualitative responses show differences related to the observed changes in teachers' lives due to lockdown. Clear differences are observed in the discourse of the two groups of teachers. On the one hand, those who report having low physical activity point out changes in their professional lives and in their relationship with students and focus on showing their concern for the greater dedication and longer working time required by online teaching. On the other hand, teachers who have more time to develop physical activity show a greater dispersion in their responses $[7,27,28]$.

It is worth mentioning that the biggest difficulties in the online training of PE teachers in all countries were mainly related to the technical support in the process: a lack of proper equipment at home (laptop, tablet, speakers, headphones, microphone), a lack of proper training (how to use technology) and there was no previous experience with applications/platforms that the PE teachers could refer to. Differences in the responses of teachers from separate countries to the types of difficulties during online teaching are related to specificity of the educational system and the different support from the respective institutions.

PE teachers from all countries agree that the lack of support from classmates and the size of the class are significant problems in online teaching.

The pandemic greeted teachers largely unprepared for a full transition to online learning. In most cases, there were no specialised courses for those working in an educational Internet environment, and PE teachers had to learn from their colleagues and acquaintances themselves. Personal competences and knowledge of teachers how to use technology is also one of the important factors for the motivation or demotivation of teachers for online teaching and the quality of the online teaching process. The results from our study suggest that there is a strong need for a systematic approach in education of teachers for the use of information technology (IT) in the teaching process, considering that $83 \%$ reported a need of proper training on the use of technology. Meanwhile, it might be encouraging that most of the teachers are proactive and reported that they worked on their skills alone or supported by colleagues or other persons not related to schools. 
The importance of technology-competent teachers is emphasised in many studies that involved some forms of implementation of technology in PE teaching before the pandemic [24,29-31] and is more evident during the pandemic period when the use of mobile applications, online video exercises, short sitting breaks, and self-monitoring training applications are highly recommended [32]. Our study also focused on teachers' personal concerns regarding online PE teaching, considering it was a new concept of teaching. Teachers' concerns about child safety during online teaching and use of materials and resources that are their intellectual property raise problems and issues that were not experienced before. In addition, a more critical approach among secondary PE teachers towards the negative consequences of the online teaching could be probably linked to the more difficult online communication with adolescents, as well as the more-often-occurring problems that accompany the training in a specific electronic environment. In such a situation, support from colleagues and school management is essential. Proper delivery of curriculum was also reported as one of the concerns by many of teachers from all countries involved in the study.

PE in all the studied countries addresses the need to provide pupils with opportunities to be physically active and develop motor competency for participation in lifelong physical activity, as well as the need to encourage young people to lead active and healthy lifestyles by focusing on physical, mental, intellectual, and social development [21]. According to the results in this study, such orientation of the subject was maintained during online teaching, with emphasis on the health component. Particularly, teachers were mainly focused on encouraging students to promote healthy behaviour (51.1\%), supporting students in their needs related to physical activity and health (49.1\%), raising students' awareness of the importance of health behaviours $(47.0 \%)$, and supporting students in maintaining their physical fitness in difficult conditions $(47.0 \%)$. Regardless of many difficulties reported during online teaching, encouraging the clear focus of most of the interviewed teachers on health-promotion using movement and physical activity, as manner to cope with COVID-19.

The lower activity found in teachers and students during the first lockdown of the COVID-19 pandemic was a result of the restrictions imposed and the increased antiepidemic measures in the individual countries. The measures taken had a direct impact on the data obtained. Similar to our study, the decreased level of physical activity of children during the pandemic and online teaching were also reported for children in other countries, such as Slovenia [33], Canada [34], Spain, and Brazil [35]. A decreased level of physical activity was followed by longer screen time, less time outdoors [34], and increased sleep duration [35].

The pandemic also affected teachers' motivation for work, who reported reduced motivation for work [8]. It should be underlined that the PE is the only subject in the educational system that is associated with the aim of increasing physical activity and with a high emotional context, which is difficult to be achieved in online PE process.

This study has several strengths. First, it provides an overview of the online education of PE teachers during the first lockdown. Moreover, it provides an international view on the situation, with a sample of teachers from six countries. It also identifies the critical points in the work of PE teachers during distance PE teaching. Identifying these weaknesses, we have a clear idea what should be improved, changed, or modified. Yet, the study has its limitations. They mainly refer to the included sample, the subjective opinion of teachers, and the period of realisation. The sample of participants per country does not allow a generalisation of the results, although it is a good starting point for future studies. The survey findings represent the personal opinions of PE teachers and having in mind the period of realisation (the first wave of the pandemic), where most of the things were uncertain and unknown, give space for great subjectivity that can vary from the personal condition of teachers in that particular period. Another potential limitation is a selection bias; it is possible that the PE teachers who participated in our study may be particularly interested in the topic of our study or/and more prone to technology. A 
repeated study from today's perspective, one year after the first lockdown, could give a better understanding of the changes that occurred in online PE teaching. Future studies should aim to analyse the changes in the PE teachers' opinion about online teaching over the time, and with the experience gained. Further research is needed in order to examine whether male and female teachers or teachers with less or more teaching experience differ in their opinion to online teaching in PE in the conditions of the COVID-19 lockdown.

\section{Conclusions}

The presented study gives a comparative overview of PE teachers' opinions about online PE teaching during the first wave of the COVID-19 pandemic. It presents opinions of PE specialist teachers from Poland, North Macedonia, Croatia, Turkey, Bulgaria, and Kosovo. The study results suggest differences in the evaluation of online teaching between PE teachers from different countries, a positive evaluation of online teaching reported by teachers from Croatia, Poland, and Bulgaria, neutral in Turkey, and a negative evaluation during that period by teachers in Macedonia and Kosovo. Different ratings of advantages, disadvantages, and difficulties between PE teachers from the studied countries in online teaching in primary and secondary schools were also noted. A lack of proper equipment at home, a lack of proper training for IT use, as well as the use of different platforms for online teaching were among the highest ranked difficulties during online teaching. This is supplemented with a reported decrease in the physical activity levels of children in all countries, as well as general decrease in the motivation for work reported by the teachers. The greatest concerns during online PE teaching were identified in terms of pupils' safety, intellectual property of resources, and quality of curriculum delivery. The results from the study identify the most important areas of teachers' work where PE should be supported regarding online teaching.

Future research should focus on comparing the attitudes of PE teachers towards online teaching during the first and the second lockdown of the COVID-19 pandemic. Another trend is to expand the study to include more European countries.

Supplementary Materials: The following are available online at https:/ /www.mdpi.com/article/10 $.3390 /$ su132111730/s1, Table S1: The open-ended answers of the study participants in terms of the most important advantages of online PE; Table S2: The open-ended answers of the study participants of the most important negative consequences of online PE; Table S3: The open-ended answers of the study participants of the biggest difficulties of online PE.

Author Contributions: Conceptualisation, A.K., J.K., M.Ł. and M.B.; methodology, A.K., J.K., M.Ł. and M.B.; formal analysis, A.K., J.K. and M.B.; investigation, A.K., J.K., M.E. and M.B.; data collection, A.K., J.K., M.Ł., B.P., H.P., B.F., E.M., A.R.K. and M.B.; writing—original draft preparation, A.K., J.K., M.Ł., B.P., H.P., B.F., E.M., A.R.K. and M.B.; writing-review and editing, A.K., J.K., M.Ł., B.P., H.P., B.F., E.M. and M.B.; visualisation, A.K. and M.B.; supervision, M.B.; project administration, A.K. All authors have read and agreed to the published version of the manuscript.

Funding: No funding to declare.

Institutional Review Board Statement: The study was conducted in accordance with the Declaration of Helsinki.

Informed Consent Statement: All participants were duly informed about the study and took part voluntarily, where all testing was completed anonymously. By completing the survey, they were agreeing to participate in the study.

Data Availability Statement: Data is available upon request from the corresponding author.

Acknowledgments: The cooperation of educational institutions in Poland, Croatia, North Macedonia, Turkey, Bulgaria, and Kosovo, and of Physical Education teachers are greatly appreciated.

Conflicts of Interest: The authors declare no conflict of interest. 


\section{References}

1. Guragai, M. Nepalese Medical Students in the COVID-19 Pandemic: Ways Forward. J. Nepal Med. Assoc. 2020, 58, 352-354. [CrossRef] [PubMed]

2. WHO. Responding to Community Spread of COVID-19: Interim Guidance. 2020. Available online: https://www.who.int/docs/ defaultsource/coronaviruse/20200307responding-to-COVID-19communitytransmission-final.pdf (accessed on 3 March 2021).

3. UNESCO. COVID-19 Educational Disruption and Response. 2020. Available online: https://en.unesco.org/covid19/ educationresponse (accessed on 3 March 2021).

4. Daniel, S.J. Education and the COVID-19 pandemic. Prospects 2020, 49, 91-96. [CrossRef]

5. Reimers, F.M. What the Covid-19 Pandemic Will Change in Education Depends on the Thoughtfulness of Education Responses Today. Worlds of Education. 2020. Available online: https://www.worldsofeducation.org/en/woe_homepage/woe_detail/ $16727 / \%$ E2\%80\%-9Cwhat-the-covid-19-pandemic-will-change-in-education-depends-on-the-thoughtfulness-of-educationresponses-today\%E2\%80\%9D-by-fernando-m-reimers (accessed on 3 March 2021).

6. Roe, A.; Blikstad-Balas, M.; Dalland, C.P. The Impact of COVID-19 and Homeschooling on Students' Engagement with Physical Activity. Front. Sports Act. Living 2021, 2, 589227. [CrossRef]

7. Varea, V.; González-Calvo, G. Touchless classes and absent bodies: Teaching physical education in times of Covid-19. Sport Educ. Soc. 2021, 26, 831-845. [CrossRef]

8. Gobbi, E.; Maltagliati, S.; Sarrazin, P.; Di Fronso, S.; Colangelo, A.; Cheval, B.; Escriva-Boulley, G.; Tessier, D.; Demirhan, G.; Erturan, G.; et al. Promoting Physical Activity during School Closures Imposed by the First Wave of the COVID-19 Pandemic: Physical Education Teachers' Behaviors in France, Italy and Turkey. Int. J. Environ. Res. Public Health 2020, 17, 9431. [CrossRef]

9. Lau, P.W.; Lau, E.Y.; Wong, D.P.; Ransdell, L. A Systematic Review of Information and Communication Technology-Based Interventions for Promoting Physical Activity Behavior Change in Children and Adolescents. J. Med. Internet Res. 2011, 13 , e48. [CrossRef]

10. Mannocci, A.; D’Egidio, V.; Backhaus, I.; Federici, A.; Sinopoli, A.; Varela, A.R.; Villari, P.; La Torre, G. Are There Effective Interventions to Increase Physical Activity in Children and Young People? An Umbrella Review. Int. J. Environ. Res. Public Health 2020, 17, 3528. [CrossRef]

11. Koh, K.T.; Tan, L.Q.W.; Camiré, M.; Paculdar, M.A.A.; Chua, W.G.A. Teachers' and students' perceptions of factors influencing the adoption of information and communications technology in physical education in Singapore schools. Eur. Phys. Educ. Rev. 2021. [CrossRef]

12. Daum, D.N.; Buschner, C. The Status of High School Online Physical Education in the United States. J. Teach. Phys. Educ. 2012, 31, 86-100. [CrossRef]

13. Kooiman, B.J.; Sheehan, D.P.; Wesolek, M.; Retegui, E. Moving online physical education from oxymoron to efficacy. Sport Educ. Soc. 2017, 22, 230-246. [CrossRef]

14. Mosier, B.; Lynn, S. An initial exploration of a virtual personal fitness course. Online J. Distance Learn. Adm. 2012, 15, 1-11. Available online: http:/ / www.westga.edu/ \{\}distance/ojdla/fall153/mosier_lynn153.html (accessed on 3 March 2021).

15. Williams, L. A Case Study of Virtual Physical Education Teachers' Experiences in and Perspectives of Online Teaching. Ph.D. Thesis, University of South Florida, Tampa, FL, USA, 2014.

16. Williams, L.; Martinasek, M.; Carone, K.; Sanders, S. High School Students' Perceptions of Traditional and Online Health and Physical Education Courses. J. Sch. Health 2020, 90, 234-244. [CrossRef]

17. Declaration of Helsinki. Available online: https://www.wma.net/what-we-do/medical-ethics/declaration-of-helsinki/ (accessed on 21 October 2020).

18. Naydenova, K.; Chernev, K. Distance learning in the conditions of COVID-19, the point of view of students and pupils. Pedagogy 2020, 92, 260-267.

19. Bronikowska, M.; Krzysztoszek, J.; Łopatka, M.; Ludwiczak, M.; Pluta, B. Comparison of Physical Activity Levels in Youths before and during a Pandemic Lockdown. Int. J. Environ. Res. Public Health 2021, 18, 5139. [CrossRef] [PubMed]

20. Zheng, C.; Huang, W.Y.; Sheridan, S.; Sit, C.H.-P.; Chen, X.-K.; Wong, S.H.-S. COVID-19 Pandemic Brings a Sedentary Lifestyle in Young Adults: A Cross-Sectional and Longitudinal Study. Int. J. Environ. Res. Public Health 2020, 17, 6035. [CrossRef] [PubMed]

21. MacPhail, A.; Tannehill, D.; Avsar, Z. European Physical Education Teacher Education Practices: Initial, Induction, and Professional Development; Meyer \& Meyer Sport: Maidenhead, UK, 2019.

22. Hall, C.M.; Bierman, K.L. Technology-assisted interventions for parents of young children: Emerging practices, current research, and future directions. Early Child. Res. Q 2015, 33, 21-32. [CrossRef] [PubMed]

23. González, C.S.; Gómez, N.; Navarro, V.; Cairós, M.; Quirce, C.; Toledo, P.; Marrero-Gordillo, N. Learning healthy lifestyles through active videogames, motor games and the gamification of educational activities. Comput. Hum. Behav. 2016, 55, 529-551. [CrossRef]

24. Edginton, C.R.; Chin, M.K.; Demirhan, G.; Asci, H.; Bulca, Y.; Erturan-Ogut, E. Global forum for physical education pedagogy 2016-Technology, networking and best practice in physical education and health: Local to global. Int. J. Phys. Educ. A Rev. Pub. 2016, 3, 28-48.

25. Gallè, F.; Sabella, E.A.; Ferracuti, S.; De Giglio, O.; Caggiano, G.; Protano, C.; Valeriani, F.; Parisi, E.A.; Valerio, G.; Liguori, G.; et al. Sedentary Behaviors and Physical Activity of Italian Undergraduate Students during Lockdown at the Time of CoViD-19 Pandemic. Int. J. Environ. Res. Public Health 2020, 17, 6171. [CrossRef] 
26. Maltagliati, S.; Carraro, A.; Escriva-Boulley, G.; Bertollo, M.; Colangelo, A.; Papaioannou, A.; Fronso, S.; Cheval, B.; Gobbi, E.; Sarrazin, P. Changes in physical education teachers' motivations predict the evolution of behaviors promoting students' physical activity during the COVID-19 lockdown. SportRxiv 2021. [CrossRef]

27. Santillán-Marroquín, W. El teletrabajo en el COVID-19. CienciAmérica 2020, 9, 65-76. [CrossRef]

28. Aperribai, L.; Cortabarria, L.; Aguirre, T.; Verche, E.; Borges, Á. Teacher's Physical Activity and Mental Health During Lockdown Due to the COVID-2019 Pandemic. Front. Psychol. 2020, 11, 577886. [CrossRef]

29. Glapa, A.; Grzesiak, J.; Laudanska-Krzeminska, I.; Chin, M.-K.; Edginton, C.R.; Mok, M.M.C.; Bronikowski, M. The Impact of Brain Breaks Classroom-Based Physical Activities on Attitudes toward Physical Activity in Polish School Children in Third to Fifth Grade. Int. J. Environ. Res. Public Health 2018, 15, 368. [CrossRef] [PubMed]

30. Popeska, B.; Jovanova-Mitkovska, S.; Chin, M.-K.; Edginton, C.R.; Mok, M.M.C.; Gontarev, S. Implementation of Brain Breaks ${ }^{\circledR}$ in the Classroom and Effects on Attitudes toward Physical Activity in a Macedonian School Setting. Int. J. Environ. Res. Public Health 2018, 15, 1127. [CrossRef] [PubMed]

31. Mok, M.M.C.; Chin, M.-K.; Korcz, A.; Popeska, B.; Edginton, C.R.; Uzunoz, F.S.; Podnar, H.; Coetzee, D.; Georgescu, L.; Emeljanovas, A.; et al. Brain Breaks®Physical Activity Solutions in the Classroom and on Attitudes toward Physical Activity: A Randomized Controlled Trial among Primary Students from Eight Countries. Int. J. Environ. Res. Public Health 2020, $17,1666$. [CrossRef] [PubMed]

32. Jakobsson, J.; Malm, C.; Furberg, M.; Ekelund, U.; Svensson, M. Physical Activity During the Coronavirus (COVID-19) Pandemic: Prevention of a Decline in Metabolic and Immunological Functions. Front. Sports Act. Living 2020, 2, 57. [CrossRef] [PubMed]

33. Jurak, G.; Morrison, S.A.; Kovač, M.; Leskošek, B.; Sember, V.; Strel, J.; Starc, G. A COVID-19 Crisis in Child Physical Fitness: Creating a Barometric Tool of Public Health Engagement for the Republic of Slovenia. Front. Public Health 2021, 9, 644235. [CrossRef]

34. Moore, S.A.; Faulkner, G.; Rhodes, R.E.; Brussoni, M.; Chulak-Bozzer, T.; Ferguson, L.J.; Mitra, R.; O’Reilly, N.; Spence, J.C.; Vanderloo, L.M.; et al. Impact of the COVID-19 virus outbreak on movement and play behaviours of Canadian children and youth: A national survey. Int. J. Behav. Nutr. Phys. Act. 2020, 17, 85. [CrossRef]

35. López-Gil, J.; Tremblay, M.; Brazo-Sayavera, J. Changes in Healthy Behaviors and Meeting 24-h Movement Guidelines in Spanish and Brazilian Preschoolers, Children and Adolescents during the COVID-19 Lockdown. Children 2021, 8, 83. [CrossRef] 